\title{
Research of Oil Spill Response Technology
}

\author{
Tong $\mathrm{Wu}^{1, \mathrm{a}}$, Hongbo Zheng ${ }^{1, \mathrm{~b}_{*}}$, Shushen Zhang ${ }^{1, \mathrm{c}}$, Shuming $\mathrm{Ma}^{1, \mathrm{~d}}$ \\ ${ }^{1}$ Key Laboratory of Industrial Ecology and Environmental Engineering (MOE), School of \\ Environmental Science and Technology, Dalian University of Technology, 2 Linggong Road, Dalian \\ 116024, China \\ aqudwtong@126.com, bdlhongbo@126.com, 'czhangss@dlut.edu.cn, dshuming_ma@126.com
}

Keywords: Oil spill response technology, Marine oil spill, Port oil spill, Tideland oil spill , Shoreline oil spill, Land oil spill.

\begin{abstract}
Frequent occurrences of marine ship oil spill accidents have brought great damage to the socio-economy and ecological environment. When an oil spill accident happens, port, tideland, shoreline and land might be polluted as oil slick is drifting constantly. This article analyzes the featuers of the four areas poll spill and the technical measures of contingency response comprehensively.
\end{abstract}

\section{Introduction}

The active marine oil transportation has led to the frequent occurrence of oil spills. Once an oil spill accident happens, crude oil and its derivatives will impose a potential threat to aquatic environments[1]. Effected by the wave and the tide, oil slick will spread and flow constantly. Port, tideland, shoreline and land will be polluted if the oil was not intercepted in time. This paper aims to provide a broad review of the current technologies used to remedy oil spills, and the context in which they operate.

\section{Marine oil spill response technology}

Once oil leaked into the sea, emergency measures must be taken to reduce the damage and protect the marine environment .Marine oil spill clean-up technology has expanded to include a variety of approaches in the past 50 years[2]. Spill response techniques are typically classified as mechanical/physical, chemical, and biological[3]. Considering the clean-up technology for marine oil spill is mature relatively, no detailed description is inroduced here.

\section{Port oil spill response technology}

\subsection{The featrues of port oil spill pollute}

Ships, operating mechanical equipments, buildings and other stuffs are polluted as soon as the oil drift to the port. Quay wall builted with giant reinforced cement has many big gaps inside. As the waves lapping, large mount of oil will be squeezed into the crevices. This kind of oil is hardly to be clean up.

\subsection{Port oil spill response technology}

In the firt step, the emergency pensonals should put booms surround the port to prevent more oil entering in. At the same time, oil is gethered toghter for recovery.

If the oil slick is thick, then it can be recovered by skimmers, recovery vessels, Rotary oilcollections and so on. By this method large amounts of oil can be removed. While recovering the oil, operation staffs should not throw adsorbing materials into the sea in caes of blocking the working machines. If the oil slick is thin, suction felts can be used to cleanuo the oil.Chemical dispersants can be sprayed into the water to reduce the oil slick after getting permission from relevant departments.

There are two methods for oil in the gaps: (1) Use high-pressure water guns to wash it. (2) Drill holes in the shore and insert pipes. Then input some hot water or steam to reduce the concentration 
of oil. In this way, oil driven by the water can flow out of the gaps[4]. After using this two methods, oil slick should be removed promptly.

\section{Tideland oil spill response technology}

\subsection{The featrues of tideland oil spill pollute}

There are diverse kinds of sensitive resources distributed on the tideland. Once the tideland is contaminated by oil spill, the harm is greater than the land and oceans[5]. On the one side, the geology of tideland is so soft that oil will penetrate into sand and rocks. This will result in a harder clean-up work. On the other side, because of the poor carrying capacity, emergency personal and equipment can hardly working on the tideland, so, the oil will stay for a quite long time.

3.2 Tideland oil spill response technology

Before disposing the oil, collect relevant information and get ready.

(1) Collect relevant information, including oil spill leak, the acreage of oil slick spill drift direction and rate, etc.

(2) Collect information of sensitive resources around the contaminated area.

(3) Collect information of road conditions, terrian, landform, etc. And provide the basis for making the disposal scheme.

Oil on tideland can be removed by using equipment such as oil containment boom, oil suction felt, working ship, Amphibious oil spill recovery vehicle, vacuum pumping unit, water cannons and oil storage facilities, etc. Besides, in the process of disposal, helicopter, remote sensing satellite or manual methods should be uesd to monitor of oil spill at any time[6].

(1) Naturual Recovery

When degree of oiling is light on the tideland, and cleanup actions are likely to result in more harm than allowing the oil to be removed by natural forces, then there is no need to take action to clean the oil.

(2) Partition Processing

According to the contaminated site conditions, emergency personal should deploy oil booms to limite movements of large volumes of oil slicks to the tideland. For the region to be cleaned can be divided into several sections:

(1) In dry zones, response community can using amphibious vehicles to sweep away oil.

(2) For oil-water in the potholes, use vacuum equipment to recover preferentially.

(3) In some areas, oil viscosity is very high and its thickness can exceeds $10 \mathrm{~mm}$. For this part, if the area is small, then oil slick can be cleaned by artificial remove, othervise, by mechanical equipment.

(4) In other section, emergency personal can use oil-attracting material, dispersants and other conventional treatment methods for processing flexibly.

\section{Shoreline oil spill response technology}

Selection of specific countermeasures for use during aspill response are guided by the properties of the stranded oil, the degree of oiling, shoreline accessibility, shoreline geomorphology, mobility of available equipment, oceanographic andmeteorological conditions, and the presence of sensitive naturaland archeological resources[7].

(1) Naturual Recovery

When degree of oiling is light, when natural removal rates are very fast,or when cleanup actions are likely to result in more harm than allowing the oil to degree naturally. Naturual recovery can bo put into the practise[8].

(2) Barriers/Berms

When sensitive habitats are threatened, a physical barrier can be placed across an area to prevent oil fromr entering.

(3) Manual Oil Cleaning

Manual oil cleaning method is very suitable when there are small amounts of oil and they can be 
easily removed by non-mechanical means. Oily debris and surface oil are removed by manual means and placed in containers for subsequent disposal.Manual removal is applicable to viscous oils and weathered patches or tar balls.After removing by this method, significant amounts of oily substrate and debris may be generated. Those stuffs must be diposed in accordance with all applicable regulations[8].

(4) Mechanical Oil Removal

Mechanical oil removal method can be used when large quantities of oiled materials must be removed or oiled substrstes should be treated in other placed.In the process of mechanical removal, mechanical equipment such as front-end loaders, dredges, backhoes, elevating scrapers, and tideland cleaning machines were needed.Vehicle traffic should be controlled to minimize further oil penetration[8].

(5) Vacuuming

When liquid oil is pooled against a shoreline, stranded on the shoreline, concentrated in trenches, vacuuming method can be used in those situation to recovery the oil.to remove mobile oil pooled on shoreline substrate.Water spray systems may be used to flush the oil toward the suction head.Collected oil and oil-water mixtures would be stored temporarily prior to recycling or disposal. Large amounts of water are often collected, which requires separation and treatment[8].

(6) Flooding

When the shorelines are heavily oiled (oil is still fluid and loosely adhering to the substrate) and pebble, cobble, or boulder tidelandes are penetrated with oil,then flooding method can be a effctively way to clean up the oil. This method simulates natrual flushing. Water flows through the porous substratespushing loose oil ahead of it, and then oil comes along with water for recovery[9].

(7) Sand Blasting

When the man-made structures or solid substrates are polluted,and high-pressure, hot water, or steam cleaning is not effective and chemical cleaning is not permitted, and oil needs to be removed for aesthetic reasons, then emergency personnel can use sand blasting method to treat the pollution. Sandblasting equipment is needed to removed oil from substrste. It should be noted that used oiled sand should be transported to a designated area in case of polluting the other clean substrate[8].

(8) In Situ Burning

Oil on the shoreline can be removed by burning, particularly when it is on a combustible substrate such as logs, vegetation, and other debris. In situ burning was especially effective at the early stage of the spill event or for the oil on ice or snow. On certain substrates, it may be necessary to dig trenches to accumulate oil to a thickness that sustains burning. Before using this method, emergency personnel must consult with regulatory authorities and public health constraints. After burning, residues need to be collected[10].

\section{Land oil spill response technology}

When oil spill flows to the land, the most effective way is to ditch or take advantage of the natural ditch to collecte the oil. By this method, the nearby sensitive resources can avoid being polluted. When the oil reaches a certain amount, it should be recovered in time. After the oil is drained, response community should put some sorbent materials in the bottom of ditch to adsorb the remained oil. Then the oiled materials should be sent to a specified place.

\section{Conclusion}

Oil spills are an especially challenging chemical contamination event to remediate. The proper choice of cleanup technique is complex, and depends on a host of factors, including oil type, spill size, spill location, weather, and local regulations and standards. Choosing proper oil spill recovery methods will both minimize potential environmental damages, and reduce the uncertainty of their impacts. 


\section{Acknowledgments}

This study was supported by the Public Research Fund on Special Fund for Environmental Protection Research in the Public Interest (201209048).

\section{References}

[1] Z.X. Zhong, F.Q. You, L.H. Zhao, Oil Spill Response Planning with Consideration of Physicochemical Evolution of the Oil Slick: A Multiobjective Optimization Approach, Computers and Chemical Engineering. 35 (2011) 1614-1630.

[2] Q. Zhang, F. M. Shen, Assessing the Performance and Cost of Oil Spill Remediation Technologies. 78(2014) 233-242.

[3] D.P. Prendergast, P.M. Gschwend, V. Broje, The Response Options Calculator (ROC). International Oil Spill Conference Proceedings:1(2011)178-179.

[4] G.W. Xiong, X.L. Li, H.Z. Bai. Discussion on the Emergency Response Plan for Large Oil Spills in Port, China Maritime Safety. 4 (2012) 1673-2278.

[5] G.C. Liu, J. Yong, Oil Spill Response Training Course, Beijing:China Communications Press. 2004.

[6] S.Z. Zhao, Research on Emergency Response to Tideland Oil Spill, Transportation Science \& Technology. 1 (2014) 139-142.

[7] B.G. Shi, X.L. Li, Y.F. Wang, Research on Clean-up Technology to Typical Shoreline , China Water Transport. 5 (2013) 89-94.

[8] ASTM F2204 Standard Guide for Describing Shoreline Response Techniques

[9] S.R. Pezeshki, M.W Hester. Q. Lin, The effects of oil spill and clean-up on dominant US Gulf coast marsh macrophytes: a review. 2 (2000) 129-39.

[10] G.A. Sergy, C.C. Guenette, E.H. Owens, In-situ Treatment of Oiled Sediment Shorelines. Spill Science \& Technology Bulletin. 3(2003) 237-244. 